\title{
COMUNIDADES CRIATIVAS PARA IMPULSIONAR A PARTICIPAÇÃO COLABORATIVA NA CIDADE
}

\author{
Carla Link Federizzi \\ Unisinos \\ carlalink@gmail.com
}

\begin{abstract}
As cidades estão em constante transformação e crescimento, onde o ritmo de mudanças sociais, tecnológicas e econômicas tem se acelerado pela globalização. Neste contexto, surgem as Comunidades Criativas, que são grupos de pessoas que se reúnem - virtualmente ou fisicamente - para construir novas soluções para o seu próprio cotidiano, criando formas mais sustentáveis de viver. A partir do estudo de caso sobre o Coletivo Ocupe \& Abrace, uma comunidade criativa atuante na cidade de São Paulo, buscouse compreender quais são as dificuldades da participação colaborativa na cidade. Como resultado, foram identificadas barreiras culturais que podem guiar a atuação do designer no âmbito da cidade.
\end{abstract}

Palavras-chave: Comunidades criativas, barreiras culturais, cidades, design, Coletivo Ocupe \& Abrace.

Cities are facing social, technological and economic changes, accelerated by globalization. In this scenario Creative Communities emerge: virtual or physical groups of people that are creating sustainable solutions for their own everyday life. The research includes the case study of Ocupe \& Abrace, a creative community in São Paulo, to understand collaborative approaches in the city. The studies' purpose was to identify culture barriers that can guide design-oriented projects in the urban context.

Keywords: Creative communities, culture barriers, cities, design, Collective Ocupe \& Abrace

\section{INTRODUÇÃO}

As cidades se tornaram uma pauta importante à medida que vive-se uma fase de rápido crescimento e desenvolvimento urbano no mundo: a estimativa é que até 2030, 60\% da população mundial (5 milhões de pessoas) viverá em áreas urbanas (NEW CITIES SUMMIT, 2013). Isso tem gerado novos desafios para os governantes, que passam a lidar com problemas de maior complexidade ambiental, social, de planejamento urbano e também ligados a atividade de inovação (HAUTAMÄKI, 2010). 
Os problemas, porém, têm impactado diretamente a vida do cidadão, que passa a criar novos relacionamentos com o ambiente urbano e entre si: se tornando atores apáticos, que possuem um envolvimento prático e racional com o ambiente urbano.

Nesse cenário, é possível identificar alguns grupos de cidadãos que estão propondo práticas inovadoras, como as "Comunidades Criativas" que se organizam colaborativa e criativamente para obter resultados que levem a formas sustentáveis de viver e produzir (MERONI, 2008b). Isto é, uma iniciativa que parte das próprias pessoas, ao criar novas soluções para uma deficiência ou para uma oportunidade que melhore seu próprio cotidiano. A criatividade refere-se a novas formas de resolver os problemas, menos tradicionais e mais sustentáveis. Ou seja, novos formatos são testados, levando em consideração o bem coletivo, a utilização sustentável de recursos (humanos, ambientais e econômicos), a construção colaborativa e as novas demandas de bem-estar social (MERONI, 2008b; ROSA;WEILAND, 2013). Por mais que desejem resultados específicos, há também o intuito de melhorar a qualidade de vida social.

A partir da análise do Coletivo Ocupe \& Abrace (O\&A), um caso de uma comunidade criativa atuante na cidade de São Paulo, buscou-se compreender quais são as dificuldades da participação colaborativa na cidade. Para isso, foi desenvolvido um estudo exploratório, com coletas primárias e secundárias de dados e uma observação participante. Como resultado, espera-se inspirar ações projetuais que possam ajudar na motivação de novas comunidades e na participação ativa dos cidadãos. Isto é, compreender as possíveis formas de ação do design na formação e fortalecimento de comunidades criativas. No estudo foi possível identificar três barreiras culturais que distanciam o cidadão da cidade. $O$ artigo está estruturado em três partes: na primeira, apresenta-se o conceito de "Comunidades Criativas" baseado em Cipolla e Manzini (2009), Manzini (2008) e Meroni (2008b); na segunda, o estudo de caso do Coletivo Ocupe \& Abrace; e na terceira, as descobertas das principais barreiras culturais encontradas.

\section{DESENVOLVIMENTO}

\subsection{Comunidades Criativas}

A história mostra que as metrópoles têm alta capacidade de reivenção e que, no século XXI aumentaram as oportunidades para se tornarem mais sustentáveis e inteligentes (Leite 2012, p.8). No contexto de cidades, isso passa por criar novos relacionamentos entre o estado e sociedade para o desenvolvimento de novas políticas, novos sistemas e soluções. (Oliveira; Breda-Vázquez, 2012).

Para Cipolla e Manzini (2009), a geração de novas ideias para o ambiente urbano acontece através de "comunidades criativas", que se reúnem - virtualmente ou fisicamente - para construir novas soluções para o seu contexto. São pessoas com poder de gerar mudanças sistêmicas, a partir de novos comportamentos e percepções (BORNSTEIN, 2007). As iniciativas são baseadas em novos modelos de vida (de consumo, de organização, de práticas) diferentes dos tradicionais, e intrinsecamente mais sustentáveis, já que unem "interesses individuais com interesses sociais e ambientais" (MANZINI, 2008, p. 63).

Uma característica importante das "comunidades criativas" é que elas propõem soluções para as dificuldades do seu próprio cotidiano, isto é, "buscam ajudar 'a si 
mesmas' (ao menos em parte) 'por si mesmas'". (MANZINI, 2008, p. 68). As iniciativas são motivadas por uma visão de como o seu próprio cotidiano poderia ser diferente. $E$ é essa visão, segundo Meroni (2008b), que leva as pessoas a implementarem uma ideia, seja sozinho ou com a ajuda de outros. Então, é possível afirmar que as "comunidades criativas" estão ligadas a práticas colaborativas, de cocriação e no formato "de baixo para cima", já que nascem de uma perspectiva interna de um contexto, geralmente sem ajuda do governo, e podem evoluir para grandes escalas de atuação. Alguns autores também se referem a essas soluções como "handmade urbanism" (ROSA; WEILAND, 2013) e, em estágios de maior maturidade, como "relational services" (CIPOLLA, 2009), "empreendimentos sociais difusos" (MANZINI, 2008) ou iniciativas de "empreendedores sociais" (BORNSTEIN, 2007).

Essas iniciativas ganham força à medida que aumenta a percepção que as políticas governamentais não estão gerando soluções suficientes e/ou eficientes para os problemas enfrentados (CIPOLLA; MOURA, 2012). Além disso, há uma percepção negativa sobre o crescimento urbano atual, cada vez mais focado nos investidores e no seu lucro e, consequentemente, menos centrado nas pessoas e na sua qualidade de vida (ROSA; WEILAND, 2013). Esses dois fatores, motivam as pessoas a criarem suas próprias soluções.

O foco dessa análise são as soluções geradas pelas comunidades criativas, isto é, iniciativas que nasceram para melhorar a qualidade de vida da cidade ou de um bairro. A partir dessa revisão teórica foi possível identificar três elementos que compõem o conceito de "comunidades criativas" (figura 1): visão social, pensamento em rede e serviços colaborativos. Estes elementos podem ser encarados como estágios de maturação de um serviço, mas que se movimentam de forma sistêmica, isto é, quanto mais um serviço colaborativo for utilizado, mais fortalecerá a solução proposta, permitindo ajustes e correções no caminho. Os três elementos serão detalhados a seguir.

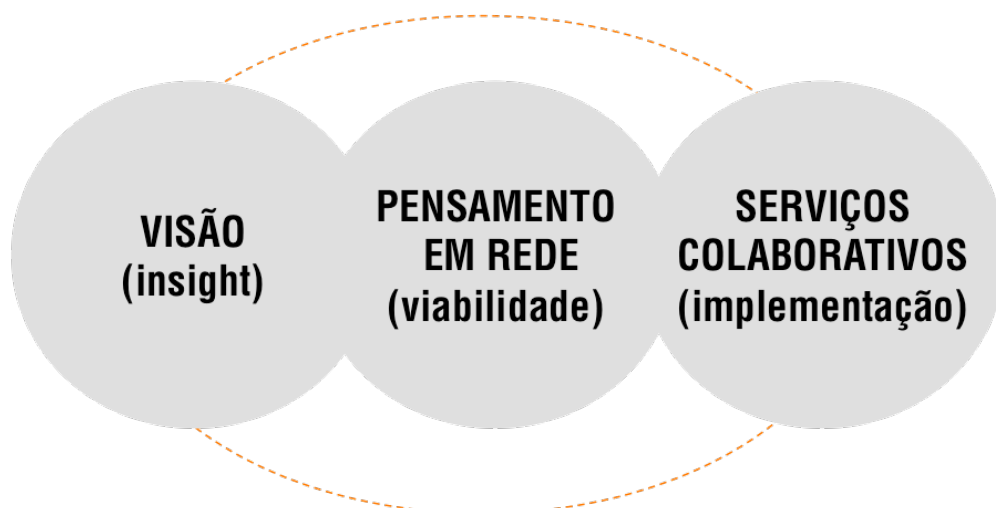

Figura 1 - Características das Comunidades Criativas.

Fonte: Elaboradora pela autora com base nos autores Baek et al. (2010), Bornstein (2007), Cipolla (2009), Cipolla e Manzini (2009), Dees (2001), Manzini (2008), Meroni (2008b).

As "comunidades criativas" mostram sua visão de mundo, suas ideias sobre o futuro e de como desenvolver soluções e serviços com os recursos disponíveis (MERONI, 2008b, p. 8). A criação desses serviços não acontece a partir da identificação de um problema, mas da visão de melhorias que podem ser colocadas em prática. Essas ideias nascem de pessoas que percebem oportunidades ou novas demandas no 
seu contexto e cotidiano, a partir da vivência de uma realidade. Dessa forma, pode-se dizer que ações de caridade ou de assistencialismo não caracterizam as soluções propostas pelas "comunidades criativas".

A essência das "comunidades criativas" está na interação entre diferentes pessoas para geração de novas formas de viver e produzir mais sustentáveis (MERONI, 2008b). Por mais que a iniciativa parta da visão de algumas pessoas, é só a partir da sua interação com os outros que ela tem valor. Segundo Cipolla e Manzini (2009), as iniciativas se caracterizam como serviços previamente organizados, que se estabelecem através de relações colaborativas entre diferentes pessoas, que criam vínculos e relações qualitativas baseadas em diálogo e confiança. À medida que a colaboração acontece e as trocas são geradas (de conhecimento, de informação e usabilidade), o serviço evolui.

A tecnologia também tem um papel importante, já que as redes têm sido utilizadas de forma intensiva para manter e gerar relacionamentos. Por um lado, a banda larga, o uso de tecnologias mobile e outros meios de comunicação permitem novos serviços; por outro, as redes sociais facilitam a troca de informações e experiências em nível global. (MURRAY, CAULIER-GRICE E MULGAN, 2010). As tecnologias, então, viabilizam serviços colaborativos e a adoção de novos comportamentos, por permitirem novos tipos de interações em tempo real.

"Relational qualities" é uma expressão que significa "diálogo genuíno" estabelecido por participantes de um serviço colaborativo a partir de confiança, intimidade, amizade e uma identidade em comum (BAEK et al, 2010). Na prática, isso significa que algumas afinidades devem existir entre os diferentes participantes, para que as trocas aconteçam de forma tranquila e transparente. Por isso, é importante estabelecer formas de diálogo entre os participantes, para que haja espaços de trocas, aprendizados e colaboração. À medida que os serviços evoluem, novos sistemas podem ser criados para fortalecer o vínculo e facilitar o convívio (CIPOLLA, 2009).

\subsection{Estudo de caso do Coletivo O\&A}

Para compreensão da problemática foi realizado um estudo de caso de natureza exploratória para gerar revelações sobre a formação e envolvimento de um grupo com a cidade, e por isso, buscou-se um caso de "Comunidades Criativas". Foram identificadas algumas iniciativas aplicadas ao contexto da Cidade de São Paulo, e decidiu-se pelo aprofundamento no Coletivo Ocupe \& Abrace, formado por moradores do Bairro Vila Pompeia que implementaram novas soluções para a região. O grupo se formou a partir da iniciativa Cidade Democrática, que por meio de uma plataforma de inovação aberta, promove concurso de ideias para diferentes cidades. Sua metodologia inclui encontros presenciais de cocriação para incentivar a produção de soluções, que possibilitou o encontro dos participantes da comunidade em questão. Esse caso foi escolhido por ter o foco na cidade de São Paulo e promover um novo modelo de participação e colaboração entre cidadãos para revitalização de um território.

Através de coletas primárias e secundárias, buscou-se compreender quais são as dificuldades de participação colaborativa na cidade e as barreiras para a formação de novas comunidades criativas. A partir do estudo, espera-se inspirar ações projetuais que possam ajudar no desenvolvimento e formação de novas 
comunidades e participações ativas na cidade. Para definição do caso foi realizado um mapeamento inicial de projetos em implementação na cidade e no estado de São Paulo, por meio de uma coleta de dados secundários. A partir da escolha foram realizadas cinco entrevistas em profundidade com participantes das três unidades de análise: cidadãos participantes, gestor da plataforma Cidade Democrática e atores do governo envolvidos, como o Subprefeito da Lapa (distrito do qual o bairro faz parte). A coleta primária também envolveu uma observação participante da iniciativa que se iniciou em Março de 2013 nos encontros presencias do Cidade Democrática até Fevereiro de 2014, e por isso, houve uma análise direta do processo de inovação ${ }^{1}$.

A análise foi desenvolvida a partir da triangulação de conteúdos, comparando a teoria analisada, os dados secundários e os dados primários coletados e a observação participante. As diferentes fontes de informações e unidades de análise auxiliam no processo de compreensão e construção dos insights. A seguir, será feito uma apresentação resumida do caso.

O grupo se formou a partir do Concurso "A Pompeia que se quer", lançado em novembro de 2013, como um concurso de ideias para o bairro Vila Pompeia, na região Oeste de São Paulo. Construir propostas coletivas baseadas nos sonhos e necessidades dos moradores, como um projeto inicial para o desenvolvimento de um plano de bairro para Vila Pompeia, era o objetivo da iniciativa. Uma das propostas geradas foi a "Revitalização da Praça Homero Silva", escolhida por alguns moradores para ser implementada. O Concurso teve o papel de aproximar os moradores entre si e do poder público, que de forma independente decidiram pela criação do Coletivo Ocupe \& Abrace.

A conexão entre os participantes se firmou pelo território, pelo interesse na construção propositiva do bairro Vila Pompeia, sob duas perspectivas: no desenvolvimento cultural e na conservação ambiental dos espaços. As atividades e projetos desenvolvidos estão relacionados a estas temáticas, aproximando moradores dos artistas da região e também das questões ambientais do bairro, como o cuidado com as águas e das áreas verdes. O Coletivo O\&A exerce um papel de articulador, mostrando o potencial criativo e sustentável do bairro para os demais moradores. A atuação do grupo está concentrada na Praça Homero Silva, rebatizada simbolicamente como "Praça da Nascente", utilizando-a como uma espécie de laboratório para testar soluções.

O Coletivo O\&A pode ser considerado um exemplo de "Comunidade Criativa", já que promove um novo modelo de construção colaborativa e sustentável para o seu próprio contexto. (CIPOLLA; MANZINI, 2009; MERONI, 2008b). Na observação foi possível perceber que o grupo está criando uma nova relação com os moradores, com o poder público e com os comerciantes do bairro. Há um desejo pela transformação positiva e coletiva sobre o território, considerando a rede estabelecida e os moradores do entorno. Isto é, a ocupação e revitalização da Praça da Nascente beneficiará os artistas, os comerciantes, os moradores, a Subprefeitura Lapa, os coletivos, etc., e também aqueles que participam propositiva e ativamente no seu desenvolvimento. $A$ construção das soluções é feita de forma experimental, aberta, criativa, colaborativa e "de baixo para cima". (MERONI, 2008b; ROSA; WEILAND, 2013).

\footnotetext{
${ }^{1}$ Este estudo é parte integrante da Dissertação de Mestrado realizada no Programa de Pós Graduação em Design da UNISINOS, titulado "Design para Inovação Social: A cidade feita pelas pessoas".
} 
Considerando os três elementos que caracterizam uma Comunidade Criativa, é possível identificar as similaridades com o Coletivo O\&A. O primeiro elemento é a visão de mundo, que representa o futuro possível percebido pelo grupo - isto é, sua ideia de como desenvolver soluções com os recursos disponíveis para o próprio contexto (MERONI, 2008b). A visão do O\&A é a construção de um novo modelo não institucionalizado e compartilhado de melhorias e uso do espaço público.

O pensamento em rede, o segundo elemento das "comunidades criativas", é a engrenagem que incentiva a interação entre diferentes pessoas, promovendo trocas de conhecimento. Para Meroni (2008b), o valor de participar de uma comunidade está nessa interação. No caso do Coletivo, a rede foi formada com o poder público, empresas locais, coletivos, grupos, artistas, universidades e outros moradores que auxiliam na implementação das soluções. Com uma postura aberta e inclusiva, qualquer pessoa pode trazer sua visão de solução para o espaço.

Suas atividades culturais e projetos de infraestrutura ambientais podem ser considerados os serviços da comunidade. Apesar de não estarem estruturados de forma tão explícita, conforme são desenvolvidos e se fortalecem, geram interesse e participação de outros moradores. A colaboração com a rede cria satisfação pela experiência vivida e pelos novos relacionamentos criados (MERONI, 2008a).

Mesmo com uma participação relativamente baixa ou pontuais (perto do potencial existente), os projetos e atividades semanais têm gerado resultados e estão atraindo mais pessoas para a Praça da Nascente. É um processo de mudança com esforços de longo prazo, isto é, à medida que há uma ocupação e construção de soluções constantes e permanentes, mais pessoas percebem e acreditam na transformação coletiva e colaborativa do espaço. Pouco a pouco, passa a inspirar moradores a proporem e idealizarem suas próprias criações, como um casamento e um aniversário de criança realizados na Praça por não membros do Coletivo O\&A. Pouco a pouco, mais pessoas estão se relacionando e se apropriando do espaço.

Porém, a mobilização de moradores no território é a principal dificuldade do grupo. Até Janeiro de 2014 havia cerca de 15 pessoas liderando e propondo projetos e atividades na Praça da Nascente e pouco mais de 50 envolvidos indiretamente. A questão central é como envolver e engajar outros moradores, em diferentes intensidades, para conhecerem e se inspirarem com o trabalho do O\&A? No estudo do caso, foi possível compreender que a baixa participação dos moradores no Coletivo O\&A se tratavam de questões mais profundas e amplas, isto é, não apenas atreladas as atividade do grupo, mas da relação do brasileiro com as questões da cidade. Assim, foi possível identificar as principais barreiras que separam o cidadão de uma postura mais ativa e propositiva na cidade.

\subsection{As barreiras culturais que dificultam a participação colaborativa}

A mudança proposta pelo Coletivo Ocupe \& Abrace ao envolver o cidadão de forma ativa e colaborativa no desenvolvimento de melhorias no espaço público vai de encontro com alguns paradigmas culturais do brasileiro, no que se refere a sua participação com as questões da cidade. Para os entrevistados, movimentos como o Cidade Democrática e o Coletivo O\&A abalam essas estruturas, porém, de forma 
tímida e pontual. Os entrevistados mostraram três pontos que são necessários considerar no comportamento do brasileiro (figura 2).

Em primeiro lugar, historicamente o Brasil diferencia os ambientes de casa e da rua (figura 2). Um dos entrevistados citou essa relação analisada por DaMatta (1997), no seu livro "A casa e a rua: espaço, cidadania, mulher e morte no Brasil", que aborda o comportamento do brasileiro ao diferenciar em duas lógicas o espaço da casa, onde tudo é permitido, pessoal e privado; e o da rua, onde é impessoal, inseguro e marginalizado. Essa percepção gera um distanciamento do cidadão com as questões da rua, já que não se sente responsável por elas.

"Criamos essa ilusão de que é ótimo viver em casa, onde posso fazer tudo: ando de meia, como sucrilhos no sofá. E que na rua tudo é péssimo, já que só tem bandido, o lugar onde não quero estar. A boa praça é o playground. A academia da rua não é boa, e sim a do meu condomínio que é vazia e não fica ninguém. DaMatta fala dessas duas lógicas e como seria bom se a gente conseguisse trazer um pouco de uma pra outra. Como trazer esse sentimento de que a rua é um lugar pra gente cuidar como se fosse nossa casa" (Gestor Cidade Democrática).

Outra questão cultural, apontada pela Chefe da Unidade de Áreas Verdes da Subprefeitura Lapa, é que o brasileiro não aprende a administrar de forma compartilhada as questões do lar, da escola e dos espaços públicos (figura 2). Desta forma, não sente responsabilidade pelas decisões tomadas nessas esferas ao longo da sua vida, o que dificulta uma formação participativa e coletiva na construção da cidade.

"Existe uma mentalidade de pai para filho no Brasil. Quantas vezes na sua família se sentou na mesa do jantar e se discutiu o problema da avó doente e a necessidade de fazer um escalamento para cuidar dela? Isso não existe, ninguém fala sobre a administração do lar. A Administração da escola também não é compartilhada. Então, não temos esses espaços para o compartilhamento de tomada de decisão, de deliberação e responsabilidade sobre aquilo que se decide" (Chefe da Unidade de Áreas Verdes da Subprefeitura Lapa).

A consequência é a transferência da responsabilidade pela conservação e organização dos espaços públicos para o Governo, que é considerado ineficiente, corrupto e lento. Há uma dependência do poder público e a expectativa que tomará a frente dos problemas da cidade. Para os entrevistados, porém, criou-se tamanho distanciamento, que o cidadão desconhece o papel e a responsabilidade de cada uma das esferas do Governo. Isto é, o que cabe à administração municipal, estadual e federal e também, ao poder executivo, legislativo e judiciário. Isto torna o processo de diálogo e planejamento de ações conjuntas para cidade mais difícil.

E o terceiro comportamento do brasileiro (figura 2), que vem se intensificando nos últimos anos, é a adoção da lógica de "condomínios fechados". Isto é, o cidadão passa a viver em áreas isoladas e com alta segurança, que o incentiva a usar o carro para resolver as questões práticas. Um dos moradores entrevistados percebe que esse comportamento é visto como um indicador de sucesso, mas que na verdade, gera um distanciamento do cidadão com os espaços de convivência da cidade. Com isso, cria-se um afastamento ainda maior entre as pessoas e as questões da cidade. 
"A pessoa tem a percepção de que 'melhorei de vida, moro num bom apartamento', mas se você analisar bem, em termos de viver a cidade não é uma melhora: ele sai pouco de casa, tem medo, só de carro, às vezes se locomove para se enfiar em outro ambiente fechado como o Shopping Center, poucas áreas verdes, parques sempre lotados. Então a pessoas não têm muitos estímulos para viver a cidade" (Fotógrafo, morador e participante do Ocupe \& Abrace).

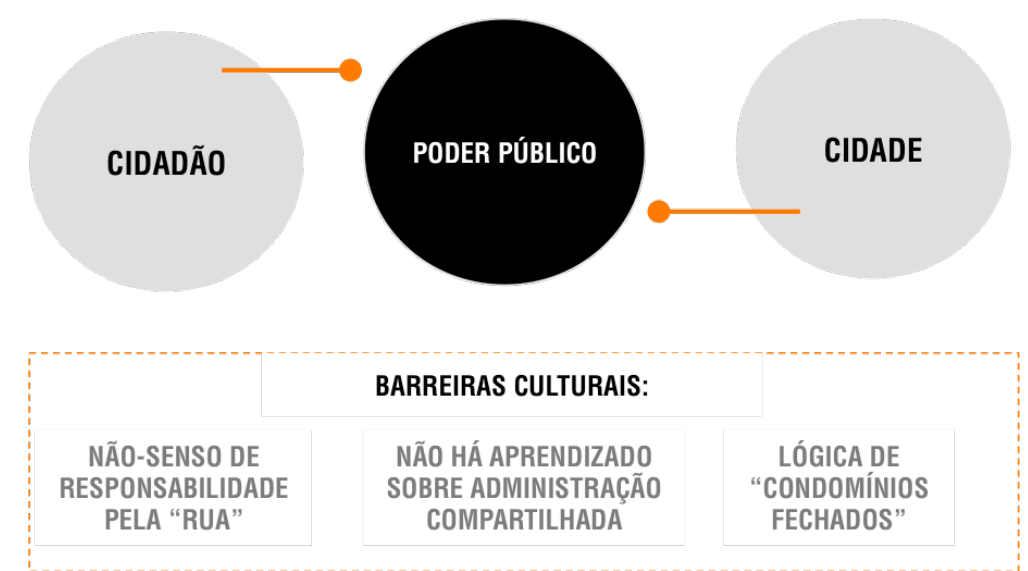

Figura 2 - Gráfico de isolamento do cidadão com a cidade.

Fonte: Elaborado pela autora, com base nas entrevistas.

Para o Subprefeito da Lapa, o ideal é construir uma "Cidade para Pessoas", conceito que, em sua visão, significa criar medidas, leis, investimentos e incentivos para que os cidadãos tenham uma experiência qualificada na cidade. Isto é, a partir do relacionamento entre os moradores, do uso do bairro, de áreas de convívio, do uso de transportes públicos, do uso do comércio local, etc. Porém, para ele São Paulo vive duas forças, que dificultam que isso se torne uma realidade: uma curva de crescimento aritmética, que representa o Governo e seus investimentos em pequena escala em cada gestão; e outra curva de projeção geométrica, ligada aos grandes investimentos imobiliários da iniciativa privada, que criam novas lógicas e transformam a cidade. Isto acarreta o enfraquecimento do poder do Governo sobre o planejamento e o futuro da cidade.

A comunidade criativa, então, pode ser um catalisador de mudanças. A partir do compartilhamento de sua visão, ela passa a inspirar pessoas a olharem criativamente para a cidade e enxergar novos futuros possíveis. Porém, no caso do Coletivo O\&A, essa construção de relacionamentos parte prioritariamente de poucos participantes e há grande dificuldade de envolver novos moradores. Os resultados mostram que são questões mais profundas e ligadas ao próprio comportamento do Brasileiro com a cidade, que se tornou mais distante e intermediada pelo poder público.

No caso estudado, a metodologia do Cidade Democrática permitiu que essas barreiras iniciais fossem ultrapassadas, criando um ambiente favorável para a formação da comunidade criativa e de novos relacionamentos entre o cidadão e o poder público. Esse ponto é importante, por mostrar que é possível projetar soluções que estimulem a participação colaborativa. A partir da compreensão dessas barreiras culturais do cidadão, é possível projetar novas formas de interação e comunicação com os cidadãos, que podem influenciar diretamente nessas questões. 


\section{CONCLUSÃO}

As cidades estão sendo palco de uma grande transformação econômica, demográfica e territorial, gerando discussões sobre como construir ambientes mais inovadores, sustentáveis e sociais (HAUTAMÄKI, 2010; LEITE, 2012). Porém, os problemas enfrentados nas cidades são complexos e de origem sistêmica, isto é, necessitam de novos modelos mentais e soluções que envolvam todos os seus atores cidadãos, instituições, empresas e governantes (CIPOLLA; MOURA, 2012). A ação isolada do poder público não é suficiente para gerar uma transformação dos sistemas urbanos, abrindo espaço para novas soluções mais criativas e contemporâneas.

Nesse contexto, a ação do design torna-se relevante, por ser reconhecido por seu processo aberto e não linear, que leva em consideração todo o sistema para a geração de novas soluções, incluindo o bem-estar das pessoas e do ambiente. (MERONI, 2008a). Por isso, justifica-se o interesse em compreender como o design pode auxiliar na formação e fortalecimento de comunidades criativas.

As comunidades se caracterizam por uma nova visão de mundo, que é traduzida em um serviço e viabilizada por meio uma rede de colaboração. Os sistemas urbanos são repensados por esses grupos que atuam ativamente e em pequena escala para a melhoria da qualidade de vida na cidade, dentro do seu próprio contexto. Para o estudo, a comunidade escolhida foi o Coletivo Ocupe \& Abrace, que se uniu com o objetivo de ocupar a Praça da Nascente, resgatando a relação dos moradores com o espaço público por meio de uma perspectiva ambiental e cultural. O estudo permitiu compreender um novo modelo de participação não institucionalizado e compartilhado, que está motivando a colaboração entre cidadãos e o poder público pela revitalização de um espaço público de São Paulo. A partir da abordagem foi possível identificar barreiras culturais que inspiram novas soluções projetuais para a construção colaborativa no território.

Um importante aprendizado é o papel inclusivo da comunidade criativa, que funciona como um agente de transformação com capacidade de despertar novos cidadãos. Isso acontece porque a visão da comunidade é compartilhada por meio de ações práticas que geram resultados reais no território. No caso estudado, apesar da rede crescer e atrair novos participantes, o grupo sente dificuldade de engajar novos membros no território. Isto é, pessoas que estejam dispostas a participar na organização, no desenvolvimento e nas propostas de iniciativas na Praça da Nascente.

Porém, um dos principais aprendizados do processo foi compreender que o envolvimento dos cidadãos precisa mudar, para que haja espaço para a inovação no contexto urbano. Isto é, a necessidade de despertar as pessoas para olharem criativamente para a cidade (MERONI, 2008b). As entrevistas mostraram que para isso acontecer é preciso tirá-las da sua zona de conforto e gerar um novo diálogo com demais moradores, governantes, instituições e o próprio espaço. Existe uma percepção de que os cidadãos não se veem como parte integrante deste sistema e com poder para impactá-lo de forma ativa e positiva. Essa dificuldade é o ponto central do problema, já que sem esse despertar não há aproximação do cidadão com a cidade ou formas de viabilizar a colaboração. Um dos entrevistados citou o conceito "cidade para pessoas" como um ideal de integração dos moradores com o espaço público, porém esse resultado mostra a necessidade de destacar a ideia de uma "cidade feita pelas pessoas". 
O estudo permitiu identificar três comportamentos ligados diretamente à cultura do brasileiro, mais especificamente do paulistano, que potencializam o desinteresse dos cidadãos. A falta de proximidade com as questões da cidade nasce de um conceito negativo sobre o espaço da "rua", que é visto como distante e de responsabilidade do poder público. Isto é atenuado por não existir uma educação/cultura de gestão compartilhada do lar ou de outras esferas da vida do cidadão. O resultado é um estilo de vida fechado e isolado dos sistemas da cidade, visto que prioriza os espaços privados e "seguros", como os condomínios fechados. Essas barreiras devem ser levadas em consideração para ativar a relação das pessoas com os espaços públicos, por meio de mecanismos e metodologias que quebram o paradigma da "não responsabilidade" e "não pertencimento" à cidade.

No caso estudado, a metodologia do Cidade Democrática permitiu que essas barreiras iniciais fossem ultrapassadas, criando um ambiente favorável para a formação da comunidade criativa. O propósito da plataforma de inovação aberta é "criar agendas públicas por meio de inteligência criativa e coletiva", isto é, desenvolver um plano de propostas para o bairro ou cidade com os sonhos e desejos dos próprios moradores. Esse pode ser o primeiro passo para criar uma visão compartilhada sobre o que é bem-estar para a região específica e impulsionar a participação dos moradores no desenvolvimento colaborativo do território.

O designer pode se inspirar nos aprendizados do estudo para desenvolver ações projetuais que possam motivar novas comunidades e a participação ativa dos cidadãos. Isto é, a partir das barreiras identificadas é possível pensar em soluções criativas que ultrapassem essas questões e criem novos relacionamentos diretos entre cidadãos e a cidade. Por exemplo, podem ser desenvolvidos aplicativos que reestabeleçam os laços entre os vizinhos e/ou uma região, criando incentivos para o consumo colaborativo ou dos comerciantes locais. Outro caminho possível é criar interferências no território com adesivos e cartazes por exemplo, incentivando o morador a ter uma visão crítica e criativa sobre o mesmo. No caso estudado, percebeu-se que o Concurso promovido pelo Cidade Democrática foi uma forma efetiva de quebrar as barreiras culturais e as atividades promovidas na Praça da Nascente conseguem atrair novos participantes a usarem os espaços públicos da cidade.

Uma das limitações do estudo, porém, foi não conseguir identificar com profundidade as características comportamentais dos cidadãos que atuam de forma colaborativa. Por exemplo, poderia ser aplicado um estudo quantitativo com os membros do Coletivo Ocupe \& Abrace para entender as motivações, formações e interesses dos participantes mais atuantes do grupo. Desta forma, podem-se revelar novas descobertas que complementam as diretrizes projetuais deste estudo, para aprimorar a ação do design nesses contextos.

\section{REFERÊNCIAS}

BAEK, J.S; MANZINI, E; RIZZO, F. Sustainable collaborative services on the digital platform: Definition and application. In: DESIGN RESEARCH SOCIETY INTERNACIONAL CONFERENCE, Montreal, 2010. Anais eletrônicos... Montreal, 2010. Disponível em: 
<http://www.drs2010.umontreal.ca/data/Program_web_06-07-10.pdf>. Acesso em: 01 mar. 2013.

BORNSTEIN, D. How to change the world: social entrepreneurs and the power of new ideas. Oxford: Oxford University Press, 2007. Disponível em: <http://books.google.com.br/books?id=P_g8gVyuuEgC\&lpg=PP1\&hl=pt-

$B R \& p g=P R 4 \# v=$ onepage \&q\&f=false $>$. Acesso em: 26 fev. 2013.

CIPOLLA, C. Relational services: service design fostering sustainability and new welfare models. In: ISSD - INTERNATIONAL SYMPOSIUM ON SUSTAINABLE DESIGN/ SBDS, 2.; SIMPÓSIO BRASILEIRO DE DESIGN SUSTENTÁVEL, 2., 2009, São Paulo. Proceedings/Anais eletrônicos... São Paulo, 2009. Disponível em: <http://portal.anhembi.br/sbds/anais/ISSD2009-015.pdf>. Acesso em: 01 mar. 2013.

CIPOLLA, C; MANZINI, E. Relational services. Knowledge Technology \& Policy, [S.I.], v. 22, p. 45-50, Springer, 2009.

CIPOLLA, C.; MOURA, H. T.; Social innovation in Brazil through design strategy. Design Management Journal, [S.I], v. 6, fasc. 1, p. 40 51, 2012. Disponível em: <http://onlinelibrary.wiley.com/doi/10.1111/j.1948-7177.2011.00020.x/abstract>.

Acesso em: 22 jan. 2013.

DAMATTA, R. A casa e a rua: espaço, cidadania, mulher e a morte no Brasil. 5 ed.- Rio de Janeiro: Rocco, 1997.

DEES, G. The Meaning of "social entrepreneurship". Center for the Advancement of Social Entrepreneurship. Duke U, 30 May 2001. Disponível em: http://www.caseatduke.org/documents/dees_sedef.pdf Acesso em: 01 mar. 13.

HAUTAMÄKI, A. Sustainable innovation: a new age of innovation and Finland's innovation policy: Sitra report 87. Helsink: Edita Prima, 2010.

LEITE, Carlos. Cidades sustentáveis, cidades inteligentes. 1. ed. São Paulo: Bookman, 2012. v. 1.

MANZINI, E. Design para inovação social e sustentabilidade: comunidades criativas, organizações colaborativas e novas redes projetuais. Rio de Janeiro: E-Papers, 2008 (Cadernos do Grupo de Altos Estudos; v. 1).

MERONI, Anna. Strategic design: where are we now? Reflection around the foundations of a recent discipline. Strategic Design Research Journal, [S.I.]. v. 1, n. 1, Dec 1, p.31-38. 2008a.

- Strategic design to take care of the territory. Networking creative communities to link people and places in scenario of sustainable development. In: P\&D DESIGN, CONGRESSO BRASILEIRO DE PESQUISA E DESENVOLVIMENTO EM DESIGN, 8., São Paulo, 2008. Anais... São Paulo, 2008b. p. 31-38.

MURRAY, R.; CAULIER-GRICE, J.; MULGAN, G. The open book of social innovation. London: NESTA/The Young Foundation, 2010. Disponível em: $<$ www.nesta.org.uk/publications/assets/features/the_open_book_of_social_innovatio n>. Acesso em: 05 Agosto 2012

NEW CITIES SUMMIT. [S.I.], 2013. Disponível em: <http://www.newcitiessummit2013.org/>. Acesso em 24 Março 2013 
OLIVEIRA, C.; BREDA-VÁZQUEZ, I. Creativity and social innovation: what can urban policies learn from sectoral experiences? International Journal of Urban and Regional Research, [S.I.], v. 36, n. 3, p. 522-538, 2012.

ROSA, M; WEILAND, U. Handmade urbanism: Mumbai - São Paulo - Istanbul - Mexico City - Cape Town: from community initiatives to participatory models. [S.I.]: Jovis: 2013. 